\title{
Xyloterus Quercus, eine neue deutsche Xylophagen-Art,
}

beschrieben von

W. Eichhoff in Hilchenbach.

Cylindricus, subbrevis, niger, antennis, pedibus, prothorace ex parte elytrisque brunneo-testaceis, his sutura, margine exteriore lineaque media nigris, thorace transversim exasperato, elytris punctatostriatis, punctis subdilatatis, interstitis inde transversim subrugulosis, antennarum clava magna, apice intus subacuminata. - Long. $1 \frac{3}{4} \operatorname{lin}$.

Noch gedrungener und fast doppelt so grofs als die gröfsten Stücke des ihm sehr ähnlichen $\boldsymbol{X}$. lineatus, besonders durch die Sculptur der Flügeldecken und die Form der grofsen Fühlerkeule von ihm nicht schwer zu unterscheiden.

Kopf schwarz, Stirn beim $\sigma^{\top}$ tief eingedrückt, in der Mitte mit deutlich bemerkbaren Höckerchen, beim $q$ hoch gewölbt, etwas weitläufig und grober als bei lineatus gekörnt. Fühler blafs röthlich gelb. Die zusammengedrückte Keule ist deutlich gröfser, als bei jenem, erweitert sich mehr nach vorn und es tritt der vordere Innenrand, ähnlich wie bei $\boldsymbol{X}$. domesticus, doch minder scharf zugespilzt, mehr stumpfwinkelig hervor. Brustschild blafs röthlichgelb, dessen Vorder- und Seilenränder und meist auch die Scheibe in gröfserer oder geringerer Ausdehnung schwarz oder schwärzlich braun. Die Form desselben ist der des lineatus gleich, also beim $ð$ querquadratisch mit wenig gebogenem Vorderrand, beim $q$ mehr kugelig, nach vorne stärker im Bogen erweitert. Die höckerartigen Querrunzeln sind merklich gröber und die Behaarung ist etwas dichter und länger als bei lineatus. Das Schildchen ist gleichseitig dreieckig, breiter als bei jenem, mit ziemlich scharfer Spitze und fast matt. Flügeldecken so breit wie das Halsschild, ziemlich glänzend, blafs gelblich braun. Die schwarzen Zeichnungen sind wie bei linealus, doch treten sie wegen der blasseren Grundfarbe deutlicher und mit schärferen Rändern hervor. Die mittlere schwarze Linie reicht nach vorn meist nur bis zur Mitte der Flügeldecken. 
Die Punkte in den Punktreihen sind merklich tiefer, treten aber dadurch, dafs sie etwas in die Breite gezogen sind, nicht scharf

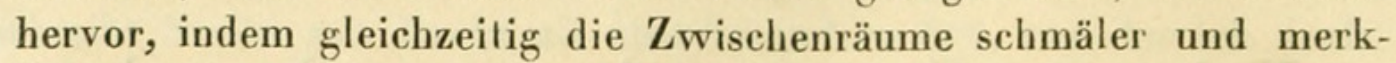
lich querrunzelig erscheinen. Die Flügeldecken sind an der Spitze ohne merklichen Eindruck mit kaum hervorragender Nath und nach den Nathwinkeln nicht vorgezogen.

Aufser den angegebenen Geschlechtsunterschieden zeichnet sich das $\delta$ noch durch stärkere, längere Behaarung, welche an der Kehle dicht bürstenartig hervortritt, vor dem $q$ aus.

Diese interessante Art, welche gleichsam den Uebergang des $\boldsymbol{X}$. lineatus zu domesticus bildet, und mit jenem mehr in der Gestalt, mit diesem mehr in Belreff der Holzart (in Laubholz), in welcher er brütet, übereinstimmt, wurde im Monat März d. J. zuerst. von einem angehenden, aber sehr gewandten Sammler, Herrn R. Becker von hier und nachher auch von mir in beinahe 100 Exemplaren, an einer alten, 2 Fufs dicken Eiche, welche schon ein Jahr lang gefällt im Walde liegt, gefunden. ${ }^{1}$ )

Die Käfer hatten ihre Brutlager schon verlassen und safsen zerstreut am Stamme umher, mit Einbohren in die Rinde begriffen. Jetzt, im Anfang Mai, sind sie eben auf den Splint gekommen. Der einzige Familiengang, welcher etwa $\frac{1}{2}$ Zoll tief im Splint mit Käfern dicht angefüllt sich vorfand, war leider bei meinem Hinzukommen bereits zerstört; scheint aber nach der mir von Herrn Becker gemachten Beschreibung denen der verwandten Arten sehr zu ähneln. Sollte nicht das wiederholt gemeldete Vorkommen des $\boldsymbol{X}$. lineatus in Birken auf einer Verwechselung mit dieser Art beruhen?

1) Ich erhielt den gewifs weit verbreiteten und bisher nur mit lineatus zusammengeworfenen Käfer von Kahr aus Tyrol oder Steyermark.

G. Kratz.

Nachtrag zu dem Verzeichnifs der europäischen Xylophagen auf pag. 46. Bd. VIII. dieser Zeitschrift.

Bei der Gattung Xyloterus ist zwischen domesticus und lineatus als neue Art $\boldsymbol{X}$. Quercus Eich. zu schreiben.

Bei Gattung Dryocaetes ist hinter fuscus Marsh. die Art Coryli Perr. zu setzen, letztere Speeies aber bei der Gattung Thamnurgus zu streichen und an deren Stelle Delphinii Ros. zu setzen.

Die letzten Berichtigungen beruhen auf der Ansicht von typischen Exemplaren. 


\section{$2 \mathrm{BHL}$ Biodiversity Heritage Library}

Eichhoff, Wilhelm Josef. 1864. "Xyloterus Quercus, eine neue deutsche Xylophagen $\square$ Art. 'Berliner entomologische Zeitschrift / herausgegeben von dem Entomologischen Vereine in Berlin 8(3प4),381-382. https://doi.org/10.1002/mmnd.18640080319.

View This Item Online: $\underline{\text { https://www.biodiversitylibrary.org/item/36390 }}$ DOI: $\underline{\text { https://doi.org/10.1002/mmnd.18640080319 }}$

Permalink: https://www.biodiversitylibrary.org/partpdf/210032

\section{Holding Institution}

Smithsonian Libraries

\section{Sponsored by}

Smithsonian

\section{Copyright \& Reuse}

Copyright Status: Public domain. The BHL considers that this work is no longer under copyright protection.

This document was created from content at the Biodiversity Heritage Library, the world's largest open access digital library for biodiversity literature and archives. Visit BHL at https://www.biodiversitylibrary.org. 